\title{
Germination and Establishment of Infection on Grape Berries by Single Airborne Conidia of Botrytis cinerea
}

\author{
S. Coertze and G. Holz, Department of Plant Pathology, and A. Sadie, Department of Biometry, University of \\ Stellenbosch, Private Bag X1, Matieland 7602, South Africa
}

\begin{abstract}
Coertze, S., Holz, G., and Sadie, A. 2001. Germination and establishment of infection on grape berries by single airborne conidia of Botrytis cinerea. Plant Dis. 85:668-677.

Table grapes (cv. Dauphine) at different phenological stages were dusted in a settling tower with dry conidia of Botrytis cinerea. The berries were incubated for periods of 3 to $96 \mathrm{~h}$ at high relative humidity ( $\mathrm{RH} ; \pm 93 \% \mathrm{RH}$, moist berries), or were covered with a film of water (wet berries). Germination of the solitary conidia, appressorium formation, stilbene and suberin induction by germlings, and germling viability were examined by fluorescence microscopy after each incubation period. Isolation and freezing studies were conducted to determine surface colonization (berries left unsterile) and penetration (surface-disinfested berries). Symptoms were determined on berries incubated at a specific wetness regime, kept dry for 10 days, and then incubated for 4 days at high RH. Microscopic observations indicated that germination was delayed on immature berries, but proceeded at a high rate on mature berries. Growth was invariably restricted on moist berries. Attempted penetration was always direct. Stilbene and suberin were generally induced early and were intense on berries at the pea-size and bunch closure stages. Dieback of conidia and germlings occurred at a significantly higher rate on wet than moist berries, and was more pronounced on immature than on mature berries. The segment isolation and freezing studies showed that infections in grape berry cheeks established by this infection mode were few. Extended incubation periods did not lead to substantially higher rates of surface colonization and skin penetration. Disease symptoms did not develop during the 14day period on the berries transferred to dry perspex chambers, irrespective of phenological stage, incubation period, or wetness regime. According to these findings, this mode of infection should not contribute to a gradual build-up of secondary inoculum in the vineyard, and to $B$. cinerea epiphytotics.
\end{abstract}

Additional keywords: conidial behavior, host resistance, infection mode, penetration, symptom expression

Botrytis cinerea, a pathogen of grape (Vitis vinifera), occurs in vineyards as sclerotia (48), conidia $(5,9)$, and mycelia $(21,52)$. Conidia are the primary inoculum for infection of berries, on which the most prominent phase of the disease is found (48). Inoculation with large numbers of conidia is used as a standard procedure in most studies where grapes are artificially inoculated. Grape bunches and berries are atomized with $(11,42,45,50)$ or dipped in (3) conidial suspensions, or suspension droplets are placed onto the berry $(6,39)$ or injected into berries $(1,40,68)$. By using these methods, different infection pathways have been described for conidial infection by $B$. cinerea on grapes, namely stigmata $(41,49)$, pedicels $(27,28,56)$, natural openings (57), wounds (45), or by direct penetration of the cuticle (51).

Corresponding author: G. Holz

E-mail address: gh@land.sun.ac.za

Accepted for publication 12 March 2001.

Publication no. D-2001-0423-03R

(C) 2001 The American Phytopathological Society
Conidia of $B$. cinerea, a facultative saprophyte, are almost always present in vineyards $(5,9)$. Conidia are primarily dispersed in air currents (32), and observations made in vineyards showed that they are deposited as single cells on spore traps (G. Holz, unpublished data). Conidia also are dispersed in splashing water droplets (33) and by insects $(18,21,38)$. In spite of the ubiquity of inoculum, data on washings made from grape berries in Californian (14) and South African vineyards (G. Holz, unpublished data) indicated that the number of $B$. cinerea conidia on berry surfaces was very low throughout the season, and $B$. cinerea occurred as single CFUs. Very few of the $B$. cinerea conidia dispersed by raindrops become wet enough to enter the droplets, and the majority are carried on the droplet surface as a dry coating (33). Conidia of $B$. cinerea attach in two distinct stages to hydrophobic surfaces $(12,13)$. The first stage, immediate adhesion, occurs upon hydration of freshly deposited conidia. Conidia of $B$. cinerea adhere more strongly when applied in water suspension or to the wet surface of grape berries than when dry conidia are applied to a dry surface (65). Raindrops may, therefore, deposit conidia carried on their surfaces as single cells onto berry surfaces during runoff. These findings imply that infection by solitary conidia, and not by conidial clusters, should play a prominent role in the epidemiology of this disease.

Results may differ following inoculation by single conidia compared to masses of conidia, and this is important in the interpretation and application of research on $B$. cinerea. Penetration by clusters of conidia at a single site could, for example, alter the host response to infection and hence the estimate of susceptibility $(20,26-28)$. In this regard, Coertze and Holz (8) demonstrated that solitary conidia are unable to induce disease symptoms on ripe cv. Dauphine table grapes. Ripe grapes are considered to be susceptible to decay by clusters of conidia $(3,23,43,50)$. If infection by single airborne conidia of $B$. cinerea is of importance in primary infection events in vineyards, the finding of Coertze and Holz (8) would have a major impact on quantitative studies involving host responses on grapevine.

Passive defense (proanthocyanidins in skins, 23; substances in berry exudates, $36,41,54,55,71)$ and active defense mechanisms (lignification-like reactions, 22; phytoalexins, 10,30,37; and suberin, 22) play an important role in the resistance of grapevine to infection by $B$. cinerea. Little is known about the behavior of single airborne conidia of $B$. cinerea on grapes at different developmental stages, and of the effect of these resistance mechanisms on infection by solitary conidia. Our objectives were to simulate natural infection by single airborne $B$. cinerea conidia and to study their germination on the berry surface, skin penetration, host resistance reactions, and symptom expression. In nature, frequent runoff of raindrops and a half day or more of sunny weather may lead to different durations of continuous fruit wetness. Therefore, trends were followed at four phenological stages at 3, 6, 12, 24, and $48 \mathrm{~h}$ postinoculation (hpi). During cold storage, fruit are usually subjected to raised temperatures during transportation, which leads to long periods ( $\geq 65 \mathrm{~h}$ ) of continuous fruit wetness (19). Therefore, additional observations were made on mature grapes at 72 and 96 hpi. Preliminary reports of this study have been published $(26,29)$. 


\section{MATERIALS AND METHODS}

Grape fruit. Grape bunches (cv. Dauphine) were selected at pea size, bunch closure $(6.3 \%$ Brix), véraison $(11.5 \%$ Brix), and harvest (16.4\% Brix) from a vineyard with a history of low $B$. cinerea disease incidence. Following harvest, the bunches were surface disinfested $(30 \mathrm{~s}$ in $70 \%$ ethanol, 2 min in $0.35 \%$ sodium hypochlorite, $30 \mathrm{~s}$ in $70 \%$ ethanol) and air dried. This treatment completely eliminated $B$. cinerea from the berry surface (60) and prevented natural infection (8). Peduncles of bunches at pea-size stage were inserted into sterile aluminum foilwrapped "oases" (florist's sponges) soaked with a $20 \%$ sucrose solution to maintain turgidity. The oases with bunches were placed on sterile epoxy-coated steel mesh screens $(53$ by 28 by $2 \mathrm{~cm}$ ). At the other developmental stages, berries were cut from clusters with short stem segments attached and packed on the steel mesh screens. To recognize the inoculated side of the berry at a later stage, a 1-cm mark was made on the berry near the pedicel with a felt-tipped pen. Previous studies (8) showed no phytotoxic effect of the ink on berries.

Inoculation. A virulent isolate of $B$. cinerea (8), obtained from a naturallyinfected grape berry, was maintained on potato-dextrose agar (PDA) at $5^{\circ} \mathrm{C}$. For the preparation of inoculum, the isolate was first grown on canned apricot halves. Co- nidiophores from the colonized fruit were transferred to PDA in petri dishes and incubated at $22^{\circ} \mathrm{C}$ under a diurnal light regime (12 h near-ultraviolet light). Conidia were harvested dry with a suctiontype collector from 14-day-old cultures and stored dry at $5^{\circ} \mathrm{C}$ for 1 to 16 weeks until used. Storage time did not affect germination (65); the dry conidia could therefore be used in all experiments. For inoculation at pea size, $5 \mathrm{mg}$ of dry conidia were dispersed in a vacuum-operated settling tower (Plexiglass, 3 by 1 by $1 \mathrm{~m}=$ height by depth by width) according to the method of Reifschneider and Boiteux (58) and allowed $3 \mathrm{~min}$ to settle onto the bunches, which were positioned in the oases on two screens. Preliminary studies (Coertze and Holz, unpublished data) showed that, at this dosage, approximately three conidia were evenly deposited as single cells on each square millimeter of berry surface. For inoculation from bunch closure to harvest stages, $3 \mathrm{mg}$ of dry conidia were dispersed by air pressure into the top of an inoculation tower (Plexiglass, 3 by 1 by $1 \mathrm{~m}=$ height by depth by width) according to the method of Salinas et al. (59) and allowed $20 \mathrm{~min}$ to settle onto the berries, which were positioned on two screens. At this dosage, approximately three conidia were evenly deposited as single cells on each square millimeter of berry surface (8). Petri dishes with water agar (WA) and PDA were placed on the floor of the settling towers at each inoculation and percent germination of conidia was determined after $6 \mathrm{~h}$ of incubation at $22^{\circ} \mathrm{C}$ (100 conidia per petri dish, three replicates). Following inoculation, the screens were placed in 12 ethanol-disinfected perspex (Cape Plastics, Cape Town, South Africa) chambers ( 60 by 30 by 60 $\mathrm{cm}$ ) lined with a sheet of chromatography paper with the base resting in deionized water to establish high relative humidity ( $\geq 93 \% \mathrm{RH})$. When fruit were pea sized, each chamber contained one screen with seven oases with bunches. Each oasis in a chamber was randomly assigned to one of the seven incubation periods. Each chamber was considered as a block. At the other developmental stages, each chamber contained seven screens with 95 berries per screen. Each screen in a chamber was randomly assigned to one of the seven incubation periods. Each chamber was considered as a block and the screens were randomized within each chamber. In six of the chambers, bunches (pea-size stage) were atomized with sterile deionized water, avoiding runoff, whereas berries (bunch closure to harvest stages) were overlaid with sterile paper towels wetted with sterile deionized water. Bunches or berries in the other six chambers were left dry. These conditions provided two wetness regimes commonly encountered in nature by the pathogen in grape bunches; dry conidia on dry berries under high RH (moist berries)
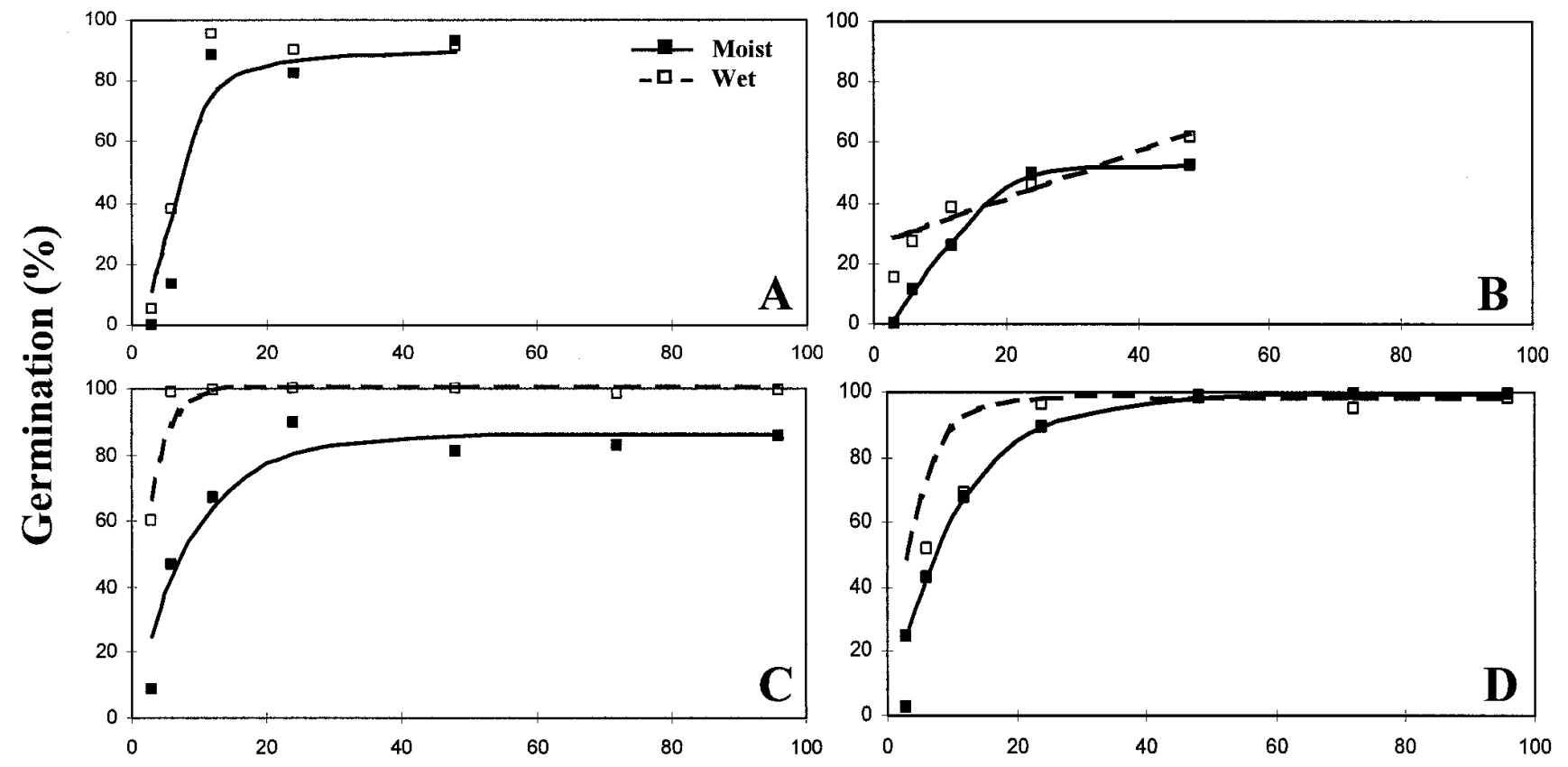

Incubation period (h)

Fig. 1. Regression models for the effects of wetness regime and incubation period on germination of solitary Botrytis cinerea conidia on cv. Dauphine grapes at different phenological stages. A, Pea-size: moist and wet $\left(Y=-26.628+34.496 \ln [X], R^{2}=0.91, P=0.0001\right)$. B, Bunch closure: moist $(Y=-$ $\left.8.616+3.532 X-0.047 X^{2}, R^{2}=0.90, P=0.0001\right)$ and wet $\left(Y=25.998+0.769 X, R^{2}=0.90, P=0.0001\right)$. C, Véraison: moist $\left(Y=86.008-86.008 \mathrm{e}^{-0.114 X}\right.$, $\left.R^{2}=0.96, P=0.0015\right)$ and wet $\left(Y=100.523-100.523 \mathrm{e}^{-0.363 X}, R^{2}=0.96, P=0.0015\right)$. D, Ripe: moist $\left(Y=99.373-99.373 \mathrm{e}^{-0.095 X}, R^{2}=0.96, P=0.0015\right)$ and wet $\left(Y=98.356-98.356 \mathrm{e}^{-0.230 X}, R^{2}=0.96, P=0.0015\right)$. Data presented are transformed means, whereas lines are predicted values based on regression equations derived from point data. Separate lines indicate significant differences in trends between treatments. 
and conidia exposed to a film of water on the berry surface (wet berries). The chambers were incubated at $22^{\circ} \mathrm{C}$ with a 12 -h photoperiod daily. After a set incubation period, the appropriate oases with bunches or screens with berries were removed from the chambers, the paper towels were removed, and the bunches and berries were air dried before they were used for histological studies and for the determination of surface colonization, skin penetration, and symptom expression.

Histology. One berry (i.e., six berries per wetness regime) was randomly detached from each bunch per chamber, or selected from each screen per chamber. Thin, hand-sectioned pieces ( 7 by $5 \mathrm{~mm}$ ) of skin comprising the cuticle, epidermis, and a few cell layers were cut with a razor blade. Fluorescein diacetate $(2 \mathrm{mg}$ per milliliter of acetone; Sigma-Adrucg, St Louis) and aniline blue $\left(0.1 \%\right.$ in $\mathrm{KH}_{2} \mathrm{PO}_{4}$ buffer, pH 5.0; BDH Laboratory Chemicals Division, Poole, England) were prepared as stock solutions and stored at -20 and $5^{\circ} \mathrm{C}$, respectively. Before a histology session, blankophor (0.5\%) Bayer, Germany) was added to the aniline blue solution and a fresh stain was prepared by mixing $25 \mu \mathrm{l}$ of the fluorescein diacetate stock solution with $1 \mathrm{ml}$ of the aniline blue-blankophor stock solution in a $1.5-\mathrm{ml}$ polypropylene tube, which was then kept on ice. The sections were stained for 5 min, mounted on a glass slide in $0.1 \mathrm{M}$ $\mathrm{KH}_{2} \mathrm{PO}_{4}$ buffer ( $\mathrm{pH}$ 5.0), and covered with a cover slip. Conidial germination, germ tube and hyphal growth, appressorium formation, penetration sites, stilbene and suberin accumulation, and viability of fungal structures were examined with a Zeiss Axioskop microscope equipped with an epifluorescence condenser, a high-pressure mercury lamp, Neofluar objectives, and Zeiss filters 02,06, and 18. These sets include excitation filters G 365, BP 436/8, and BP 395-425, respectively. With this configuration, protoplasts of viable fungal structures fluoresced brilliant yellow-green with filters 02, 06, and 18. Protoplasts of dead cells were blue-black (filters 06 and
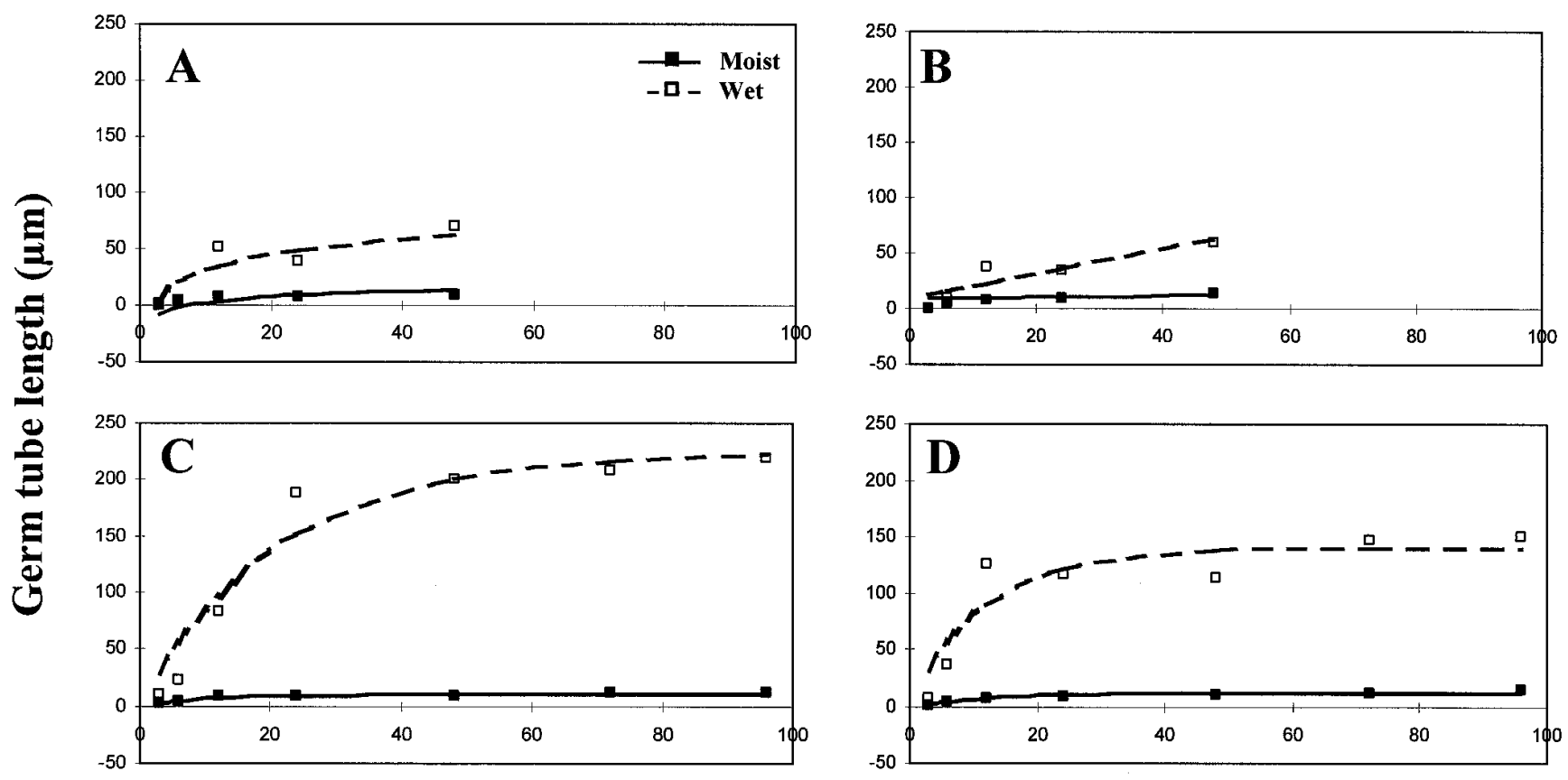

Incubation period (h)

Fig. 2. Regression models for the effects of wetness regime and incubation period on germ tube growth of solitary Botrytis cinerea conidia on cv. Dauphine grapes at different phenological stages. A, Pea-size: moist $\left(Y=-16.055+7.922 \ln [X], R^{2}=0.61, P=0.0001\right)$ and wet $(Y=-16.055+$ $\left.20.387 \ln [X], R^{2}=0.61, P=0.0001\right)$. B, Bunch closure: moist $\left(Y=9.005+0.064 X, R^{2}=0.70, P=0.0001\right)$ and wet $\left(Y=9.005+1.108 X, R^{2}=0.70, P=\right.$ 0.0001). C, Véraison: moist $\left(Y=10.786-10.786 \mathrm{e}^{-0.086 X}, R^{2}=0.98, P=0.0001\right)$ and wet $\left(Y=224.453-224.453 \mathrm{e}^{-0.046 X}, R^{2}=0.98, P=0.0001\right) . \mathbf{D}$, Ripe: moist $\left(Y=12.092-12.092 \mathrm{e}^{-0.061 X}, R^{2}=0.98, P=0.0001\right)$ and wet $\left(Y=140.000-140.000 \mathrm{e}^{-0.084 X}, R^{2}=0.98, P=0.0001\right)$. Data presented are transformed means, whereas lines are predicted values based on regression equations derived from point data. Separate lines indicate significant differences in trends between treatments.

Table 1. Percentage of germlings that developed from solitary Botrytis cinerea conidia deposited on cv. Dauphine grape berries that formed appressoria after different incubation periods under a specific wetness regime ${ }^{\mathrm{a}}$

\begin{tabular}{|c|c|c|c|c|c|c|c|c|}
\hline \multirow[b]{3}{*}{ Incubation period (h) } & \multicolumn{8}{|c|}{ Phenological stage and wetness regime $\mathrm{e}^{\mathrm{b}}$} \\
\hline & \multicolumn{2}{|c|}{ Pea-size } & \multicolumn{2}{|c|}{ Bunch closure } & \multicolumn{2}{|c|}{ Véraison } & \multicolumn{2}{|c|}{ Ripe } \\
\hline & Moist & Wet & Moist & Wet & Moist & Wet & Moist & Wet \\
\hline 3 & 1.5 & 2.0 & 1.0 & 1.0 & 0 & 0 & 0 & 0 \\
\hline 6 & 17.7 & 13.3 & 15.0 & 20.4 & 16.7 & 14.8 & 0 & 0 \\
\hline 12 & 84.6 & 29.3 & 50.3 & 30.7 & 22.3 & 34.0 & 35.0 & 4.0 \\
\hline 24 & 82.0 & 51.4 & 51.9 & 45.3 & 62.5 & 71.0 & 64.1 & 62.1 \\
\hline 48 & 84.4 & 47 & 43.8 & 52.4 & 60.5 & 97.3 & 100.0 & 87.1 \\
\hline
\end{tabular}

${ }^{a}$ Germlings with an appressorium, irrespective of appressorial type or number per germling.

${ }^{\mathrm{b}}$ Berries were dusted at pea-size, bunch closure, véraison, and ripe stage with dry conidia in a settling tower and incubated for varying periods at high relative humidity ( $\pm 93 \%$, moist berries), or were covered with a film of water (wet berries). 
18), whereas cells without protoplasts fluoresced white (filter 02) or yellow (filter 18; 53). Formation of stilbenes became visible by irradiation with UV light (filter 02), resulting in a bright blue fluorescence (37). Suberized cell walls fluoresced a light blue or bright yellow $(4,22,24,31)$. Microfissures in the skin became visible due to stilbene accumulation as well as lignification and suberization of surrounding cell walls. Stomata and lenticels were brown with yellow fluorescence of suberized cells. The sequence of events accompanying germination was observed on 30 berries (30 segments, 3,756 conidia) at pea-size stage, 30 berries (60 segments, 6,772 conidia) at bunch closure, 42 berries (84 segments, 10,233 conidia) at véraison, and 42 berries (84 segments, 11,088 conidia) at harvest.

Surface colonization, penetration, and host resistance. The effect of host resistance on surface colonization and skin penetration was determined by using a differential set of isolation and freezing techniques on berries subjected to two sterility regimes at set stages after inocula- tion. Berries from each screen were divided into two groups of 47 berries; one group on each screen was left unsterile to determine surface colonization and the other group was sterilized in $70 \%$ ethanol for $5 \mathrm{~s}$ to eliminate the pathogen on the berry surface (61) and to determine penetration. In the isolation studies (seven berries from each group on each screen), one epidermal tissue segment ( 5 by $7 \mathrm{~mm}, 21$ segments per treatment) was cut from the inoculated cheek of each berry, placed with the cuticle upward on $B$. cinerea selective medium (35), and incubated for 14 days at $22^{\circ} \mathrm{C}$. Previous studies (8) showed that uninfected skin segments retained their turgidity and remained green for 6 days, whereafter color changes indicative of natural cell death appeared. Skin segments, therefore, exuded substances to their surfaces for a considerable period and retained their active defense abilities. Under the unsterile regime, berry exudates and fungal structures were left undisturbed during the incubation period prior to and after segment removal. Conidia and germlings, therefore, confronted passive and active defense during both incubation periods. Under the sterile regime, immersion in ethanol after the initial incubation period removed the exudates and killed the fungal structures on the grape berry surface. Conidia and germlings, therefore, were influenced by passive and active defense before surface sterilization and segment removal. Thereafter, hyphae that penetrated the skin grew further despite active host defense. In the freezing studies (40 berries from each group on each screen), berries were kept for $1 \mathrm{~h}$ at $-12^{\circ} \mathrm{C}$ and incubated in a dry chamber for 14 days at $22^{\circ} \mathrm{C}$. The fungus was confronted with a different set of conditions on frozen berries. Studies (29) conducted with naturally infected and artificially inoculated berries showed that a $1-\mathrm{h}$ freezing period at $-12^{\circ} \mathrm{C}$ is needed to promote the development of latent infections. On these berries, the cuticle remained intact after freezing and provided a mechanical barrier to penetration, but the underlying cells immediately lost their ability to actively respond to the pathogen (8). Conidia and germlings under both sterility regimes
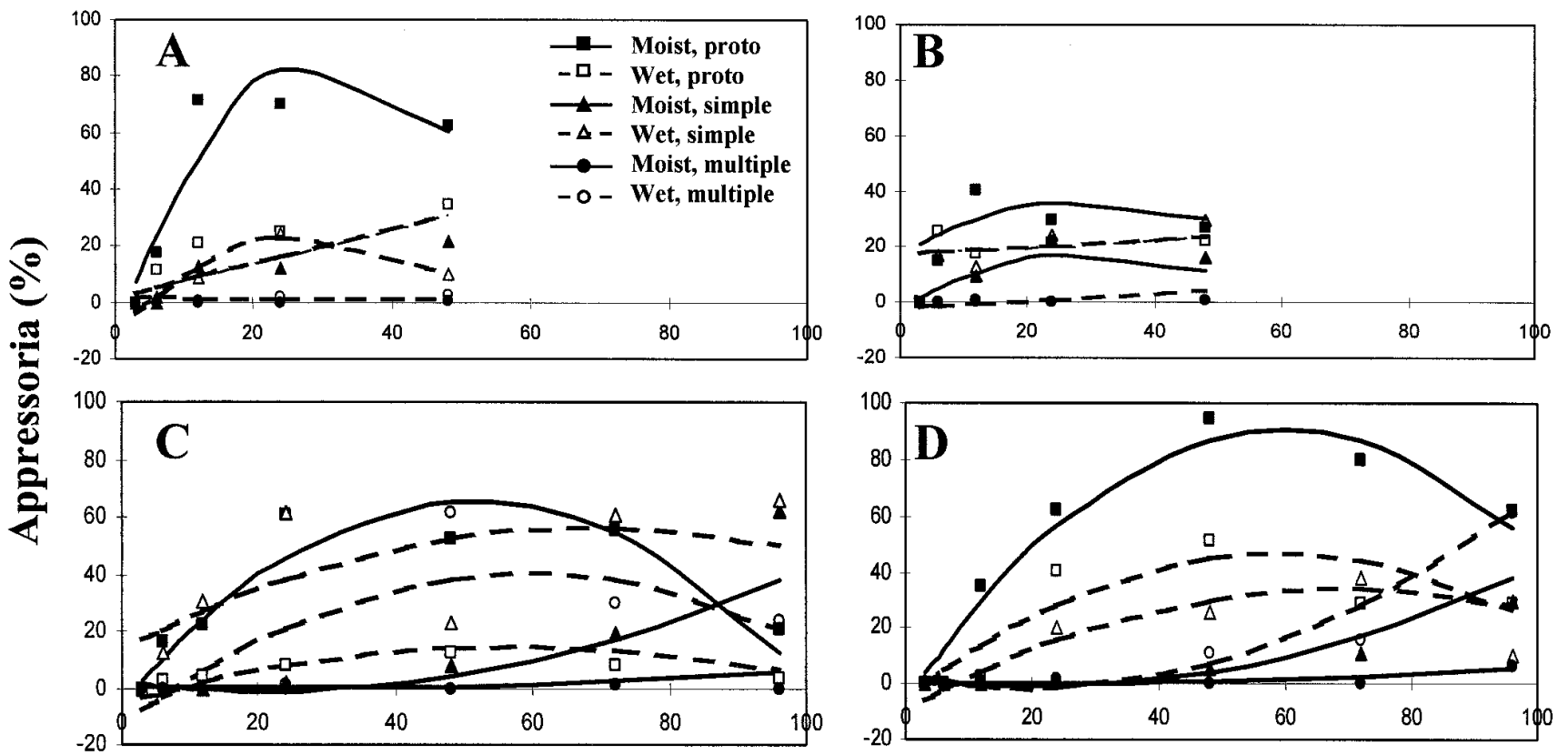

\section{Incubation period (h)}

Fig. 3. Regression models for the effects of wetness regime and incubation period on appressorium formation by solitary Botrytis cinerea germlings on cv. Dauphine grapes at different phenological stages. A, Pea-size: protoappressoria, wet, and simple appressoria, moist $\left(Y=1.1661+0.610 X, R^{2}=0.71, P=\right.$ $0.0001)$; protoappressoria, moist $\left(Y=-10.522+6.234 X-0.099 X^{2}, R^{2}=0.71, P=0.0001\right)$; simple appressoria, wet $\left(Y=-10.522+2.348 X-0.04 X^{2}, R^{2}=\right.$ $0.71, P=0.0002)$; and multiple appressoria, moist and wet $\left(Y=1.661-0.016 X, R^{2}=0.71, P=0.8742\right)$. B, Bunch closure: protoappressoria, wet, and simple appressoria, wet $\left(Y=17.196+0.128 X, R^{2}=0.67, P=0.1323\right)$; protoappressoria, moist $\left(Y=17.196+1.286-0.021 X^{2}, R^{2}=0.67, P=0.0002\right) ;$ simple appressoria, moist $\left(Y=-2.071+1.286 X-0.021 X^{2}, R^{2}=0.67, P=0.0002\right)$; and multiple appressoria, moist and wet $\left(Y=-2.071+0.128 X, R^{2}=0.67, P=\right.$ 0.1323. C, Véraison: protoappressoria, moist $\left(Y=-5.683+2.779 X-0.027 X^{2}, R^{2}=0.91, P=0.0001\right)$; protoappressoria, wet $(Y=-12.980+1.253 X-$ $\left.0.009 X^{2}, R^{2}=0.91 P=0.0013\right)$; simple appressoria, moist $\left(Y=2.073-0.295 X+0.007 X^{2}, R^{2}=0.75, P=0.5350\right)$; simple appressoria, wet $(Y=-5.683+$ $\left.0.699 X-0.006 X^{2}, R^{2}=0.75, P=0.0012\right)$; multiple appressoria, moist $\left(Y=0.412-0.041 X+0.001 X^{2}, R^{2}=0.77, P=0.7701\right)$; and multiple appressoria, wet $\left(Y=-13.505+1.800 X-0.015 X^{2}, R^{2}=0.77, P=0.0001\right)$. D, Ripe: protoappressoria, moist $\left(Y=-5.683+3.230 X-0.027 X^{2}, R^{2}=0.91, P=0.0001\right)$; protoapressoria, wet $\left(Y=-5.683+1.776 X-0.015 X^{2}, R^{2}=0.91, P=0.0001\right)$; simple appressoria, moist $\left(Y=2.073-0.295 X+0.007 X^{2}, R^{2}=0.75, P=\right.$ $0.5350)$; simple appressoria, wet $\left(Y=-9.656+1.253 X-0.009 X^{2}, R^{2}=0.75, P=0.0083\right)$; multiple appressoria, moist $\left(Y=0.412-0.041 X+0.001 X^{2}, R^{2}=\right.$ $0.77, P=0.7701)$; and multiple appressoria, wet $\left(Y=3.370-0.455 X+0.011 X^{2}, R^{2}=0.77, P=0.2548\right)$. Data presented are transformed means, whereas lines are predicted values based on regression equations derived from point data. Separate lines indicate significant differences in trends between treatments. Multiple appressoria = more than one appressorial type per germling, or multicellular, lobate appressoria, or infection cushions. 
were influenced by passive and active defense during the period before chilling, but not by active defense thereafter. Furthermore, after freezing, conidia and germlings were confronted by skin components under the unsterile regime; whereas, under the sterile regime, only fungal structures that had penetrated the skin were confronted by skin components. The number of segments or frozen berries yielding $B$. cinerea colonies were recorded in each experiment and used to quantify surface colonization, penetration, and host resistance.

Symptom expression. Screens with berries from three chambers per wetness regime were transferred to identical dry perspex chambers $(\leq 56 \% \mathrm{RH})$ for 10 days, followed by a 4-day incubation period at high RH to promote disease expression. The berries were examined daily for disease development. The number of berries with decay was recorded after 14 days.

Statistical analyses. A preliminary analysis of variance (Statistical Analysis System, Cary, NC) in a split-plot design was used to compare data in all experiments, each of which was conducted twice. Before the analyses, data were transformed using $Y=\sqrt{X+0.375}$ (74) to stabilize the variances. In cases where interactions or main effects were significant $(P \leq 0.05)$, regression analyses were performed to investigate possible significant trends in these effects. Slopes and intercepts of regression lines were subsequently compared using Student's $t$-least significant difference (LSD; $P=0.05 ; 64)$. In instances where significant differences were not found, data were combined and a single regression fitted. Results from analysis of variance and Student's $t$-LSD are not shown and only the final regression functions are given.

\section{RESULTS}

Germling growth and survival. Conidia used at each inoculation were highly viable and germinated freely on PDA and WA. Germination was consistent between 90 to $98 \%$ at $6 \mathrm{hpi}$. Germination proceeded at a lower rate on berries (Fig. 1) and followed trends which varied with grape phenology and wetness regime. Proportions of germinated conidia were lower during the 3- to 6-hpi period on immature (Fig. 1A and B) than on mature (Fig. 1C and D) berries. Berries at bunch closure (Fig. 1B) inhibited germination; on moist berries, germination peaked at $50 \%$ at 24 hpi. Germination was unaffected by wetness on pea-size berries but proceeded at a significantly higher rate on wet berries at the bunch closure, véraison, and ripe stages.

Germ tube growth under the two wetness regimes differed substantially. On moist berries, conidia germinated predominantly with one unbranched germ tube. On wet berries, they germinated with one, two, or, rarely, with up to four germ tubes that occasionally branched. Germ tube elongation followed a similar trend on moist berries at all phenological stages (Fig. 2AD) and reached maximum growth of $12 \mu \mathrm{m}$ during the 12- to 24-hpi period. Germ tube lengths, therefore, were mostly shorter or equal to that of the conidia. Germ tube growth was greater on wet berries, but varied with grape phenology. On immature berries (Fig. 2A and B), germ tubes extended slowly and reached maximum length of $60 \mu \mathrm{m}$ at $48 \mathrm{hpi}$, when elongation stopped. On mature berries (Fig. 2C and D), germ tubes extended fastest during the 3 - to 12-hpi period. Therefore, at $3 \mathrm{hpi}$, predicted length was already $\geq 10 \mu \mathrm{m}$ and maximum growth was generally achieved during the 24- to 48-hpi period.

Trends in appressorium formation followed by germlings are summarized in Table 1. Appressoria were formed earlier and their production peaked earlier on immature than on mature berries. Fewer germlings formed appressoria on berries at bunch closure than on berries at the other stages. Appressorium frequency was generally not influenced by wetness regime. The exception was on pea-size berries, where substantially more germlings formed appressoria on moist than on wet berries. Two types of appressoria were formed. On moist berries, predominantly protoappressoria and a minority of simple appressoria were formed (Fig. 3). In fact, some germlings formed a protoappressorium underneath the conidium. This was evident from the formation of blue fluorescence zones (indicative of stilbenes) that
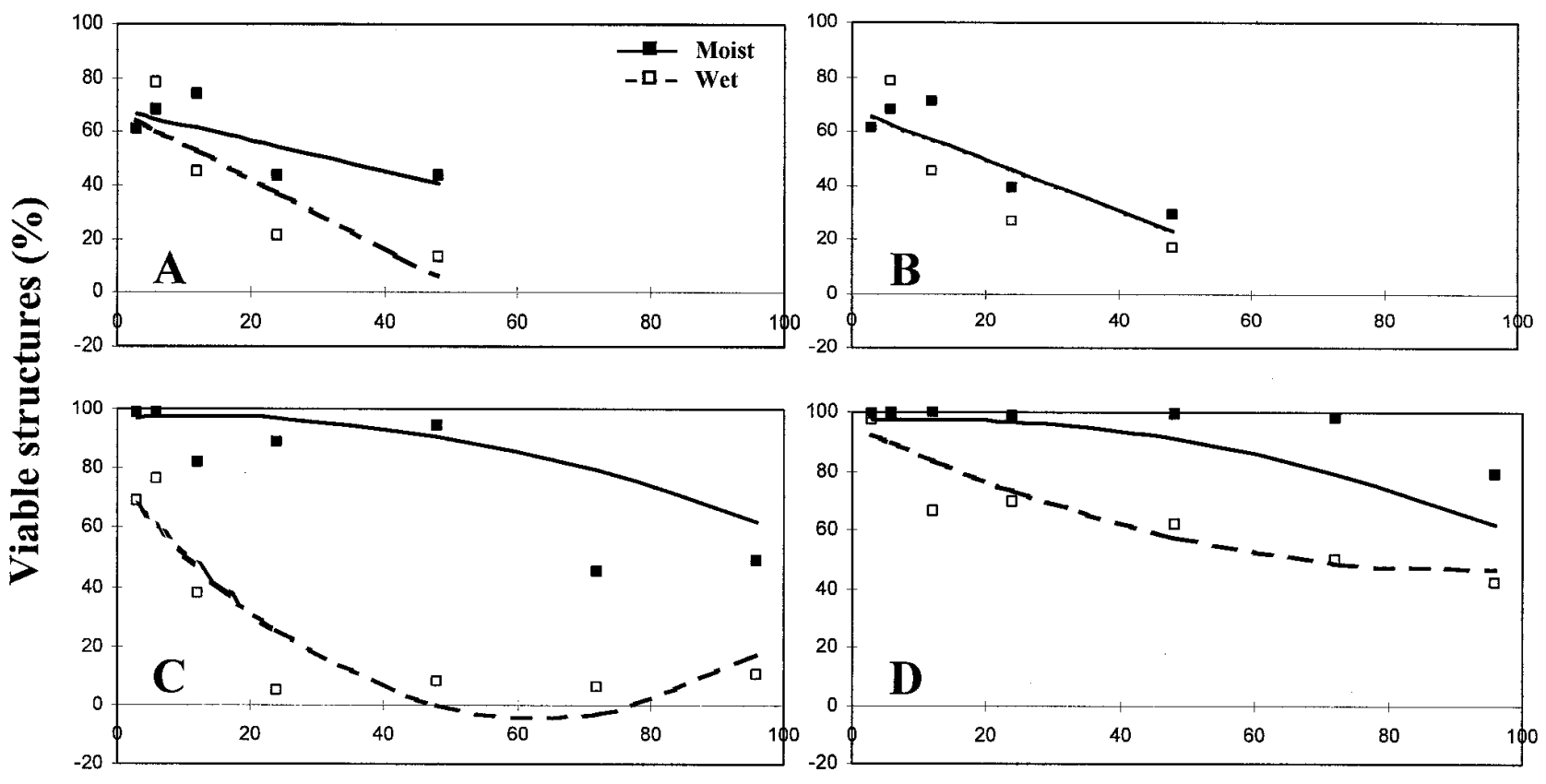

\section{Incubation period (h)}

Fig. 4. Regression models for the effects of wetness regime and incubation period on the viability of solitary Botrytis cinerea germlings on Dauphine grapes at different phenological stages. A, Pea-size: moist $\left(Y=68.373-0.573 X, R^{2}=0.80, P=0.0001\right)$ and wet $\left(Y=68.373-1.306 X, R^{2}=0.80, P=\right.$ $0.0031)$. B, Bunch closure: moist and wet $\left(Y=68.373-0.939 X, R^{2}=0.82, P=0.0001\right)$. C, Véraison: moist $\left(Y=96.853+0.117 X-0.005 X^{2}, R^{2}=0.97, P\right.$ $=0.5991)$ and wet $\left(Y=74.443-2.518 X+0.02 X^{2}, R^{2}=0.97, P=0.0001\right)$. D, Ripe: moist $\left(Y=96.853+0.117 X-0.005 X^{2}, R^{2}=0.97, P=0.5991\right)$ and wet $\left(Y=95.732-1.089 X+0.006 X^{2}, R^{2}=0.97, P=0.0002\right)$. Data presented are transformed means, whereas lines are predicted values based on regression equations derived from point data. Separate lines indicate significant differences in trends between treatments. 
appeared around some ungerminated conidia. Protoappressoria were produced first, and they were noted at very low frequencies at 3 hpi on immature berries (Fig. $3 \mathrm{~A}$ and $\mathrm{B}$ ). On wet berries, different types of appressoria were recorded: protoappressoria on short germ tubes, simple appressoria on branched germ tubes or on very short to long hyphae which had grown from germ tubes, multicellular lobate appressoria, and infection cushions. As was found on moist berries, protoappressoria were formed early and were succeeded by the other appressorial types. Multicellular lobate appressoria and infection cushions usually formed at 48 to 72 hpi after extensive superficial growth on mature berries (Fig. 3C and D).

Penetration was always direct, irrespective of wetness regime or berry ripeness. Conidia seldom landed on stomata or lenticels. In such an event, the germ tubes formed by conidia on moist berries were too short to enter these structures. On wet berries, germ tubes or hyphae usually grew around the raised stoma or lenticel. Individual germ tubes appeared to enter a stoma and then grew out again. Old microfissures were occasionally observed but did not serve as penetration sites.

Different patterns of conidium and germling dieback were observed by micro- scopic observation among individuals on a given berry. On moist berries, some conidia or germlings died, or only the conidium or short germ tube died on some germlings. A similar pattern of germling dieback was observed on wet berries. Sections of long germ tubes or branched germ tubes of some germlings died; whereas, on some germlings, the conidium stayed viable and the extended germ tube succumbed. Complete dieback was most pronounced in germlings without appressoria. Trends followed in dieback were correlated with grape phenology and wetness regime. Except for berries at bunch closure, dieback of conidia and germlings occurred at a significantly higher rate on wet than moist berries (Fig. 4). It was also more pronounced on immature than on mature berries. At pea-size stage (Fig. 4A), dieback was already noticeable at $3 \mathrm{hpi}$, when only $63 \%$ of the fungal structures were fully viable under both wetness regimes. Dieback then proceeded rapidly. At 48 hpi, only $4.7 \%$ of the fungal structures on wet berries, and $39.9 \%$ on moist berries, were viable. At véraison (Fig. 4C), dieback occurred early on wet berries, following a trend similar to the trend on immature berries. On moist berries, however, virtually no dieback occurred during the 3 to 48-hpi period. The same trend was followed at the ripe stage (Fig. 4D), except for the fact that, on wet berries, dieback proceeded at a lower rate than on berries at véraison.

Stilbene and suberin induction by germlings. Bright blue fluorescence zones, indicative of stilbenes, became visible in host cells immediately surrounding protoappressoria on short germ tubes; simple appressoria formed on branched germ tubes or on hyphae, and around multicellular lobate appressoria and infection cushions. Zones were, as a general rule, more striking when formed around proto- and simple appressoria than around multicellular appressoria. Trends in stilbene induction also varied with grape phenology. On immature berries, the fluorescence was intense and remained within discreet zones not exceeding 1 to 2 cells. On mature berries, the fluorescence was generally less intense and the zones expanded to more cells. Germlings also induced stilbene production earlier on immature (Fig. 5A and $\mathrm{B}$ ) than mature (Fig. 5C and D) berries. On immature berries, zones were observed around a minority of germlings at $3 \mathrm{hpi}$, indicating very early attempted penetration and stilbene accumulation. Stilbene induction peaked earlier ( $24 \mathrm{hpi})$ on immature berries than on mature berries (48 hpi).
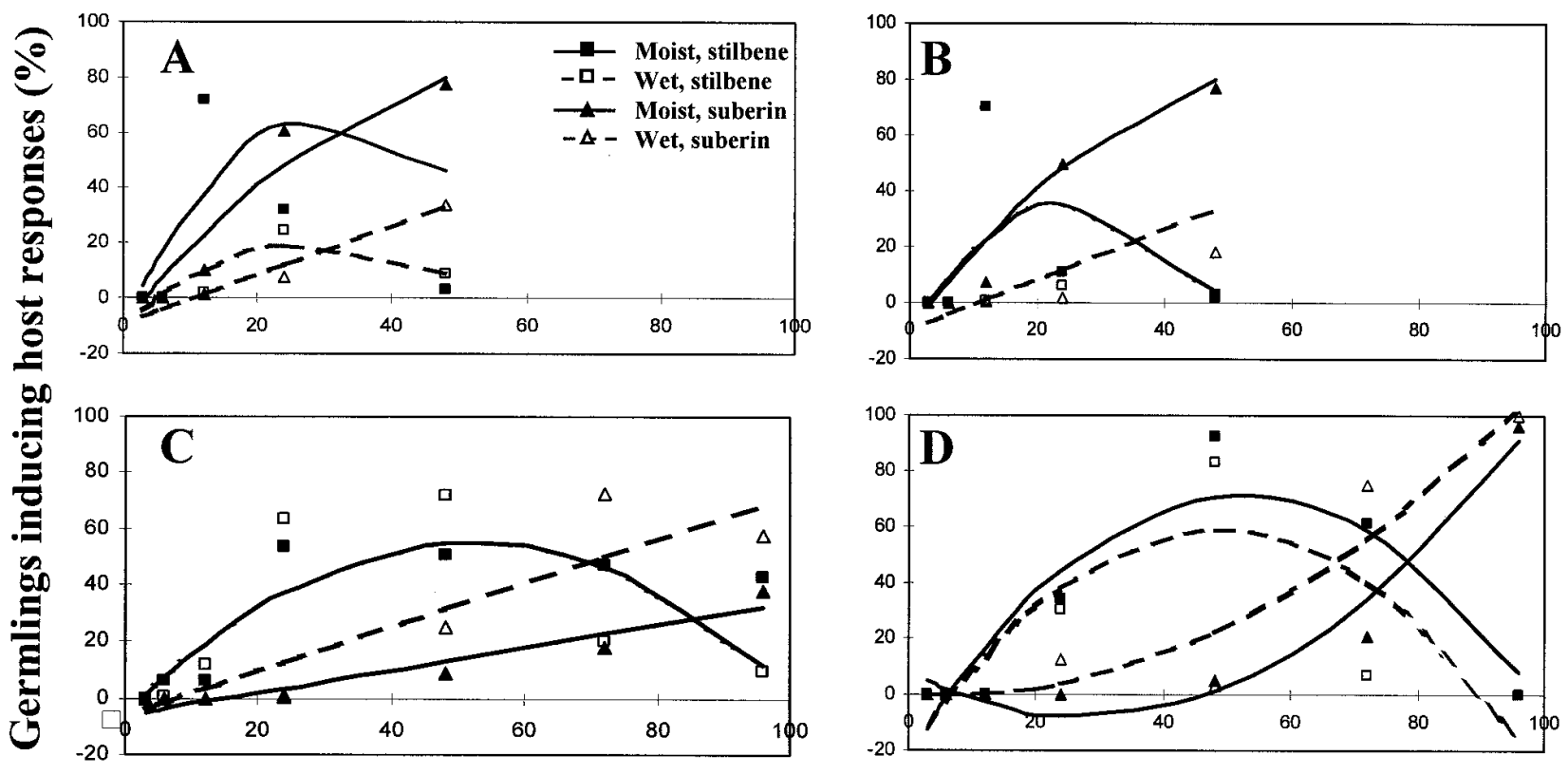

Incubation period (h)

Fig. 5. Regression models for the effects of wetness regime and incubation period on stilbene and suberin induction at penetration sites of solitary Botrytis cinerea germlings on cv. Dauphine grapes at different phenological stages. A, Pea-size: stilbenes, moist $\left(Y=-9.938+4.910 X-0.078 X^{2}, R^{2}=0.41, P=\right.$ $0.0001)$; stilbenes, wet $\left(Y=-9.938+2.024 X-0.034 X^{2}, R^{2}=0.41, P=0.0165\right)$; suberin, moist $\left(Y=-9.763+2.969 X-0.023 X^{2}, R^{2}=0.71, P=0.0001\right)$; and suberin, wet $\left(Y=-9.763+0.892 X, R^{2}=0.71, P=0.0165\right)$. B, Bunch closure: stilbenes, moist and wet $\left(Y=-9.938+3.467 X-0.066 X^{2}, R^{2}=0.43, P=\right.$ $0.0001)$; suberin, moist $\left(Y=-9.763+2.969 X-0.023 X^{2}, R^{2}=0.79, P=0.0001\right)$; and suberin, wet $\left(Y=-9.763+0.892 X, R^{2}=0.79, P=0.0001\right)$. C, Véraison: stilbenes, moist and wet $\left(Y=-5.947+2.342 X-0.0225 X^{2}, R^{2}=0.74, P=0.0001\right)$; suberin, moist $\left(Y=-6.066+0.400 X, R^{2}=0.90, P=0.0001\right)$; and suberin, wet $\left(Y=-6.066+0.776 X, R^{2}=0.90, P=0.0001\right)$. D, Ripe: stilbenes, moist $\left(Y=-20.699+3.497 X-0.0333 X^{2}, R^{2}=0.74, P=0.0001\right)$; stilbenes, wet $\left(Y=-20.699+3.244 X-0.0333 X^{2}, R^{2}=0.74, P=0.0001\right)$; suberin, moist $\left(Y=8.150-1.149 X+0.021 X^{2}, R^{2}=0.90, P=0.0001\right)$; and suberin, wet $\left(Y=0.811-0.181 X+0.013 X^{2}, R^{2}=0.90, P=0.4625\right)$. Data presented are transformed means, whereas lines are predicted values based on regression equations derived from point data. Separate lines indicate significant differences in trends between treatments. 
A light blue or bright yellow fluorescence in host cells immediately surrounding appressoria was indicative of suberization at infection sites. Suberin usually showed up in the walls of one to two cells surrounding the appressorium, and in intense reactions also in the cytoplasm of those cells. Suberization was generally more prominent when formed around proto- and simple appressoria than around multicellular appressoria. Trends in suberization also varied with grape phenology and was observed on immature berries (Fig. 5A and B) at 6 to $12 \mathrm{hpi}$ and at 12 to 24 hpi on berries at vérasion (Fig. 5C). At the ripe stage, suberin accumulation was observed on berries during the 24- to 48hpi period (Fig. 5D).

Surface colonization, penetration, and host resistance. Colonization patterns displayed by segments obtained from berries under the unsterile regime showed that surface colonization was influenced by both wetness regime and host phenology (Fig. 6A-D). Free water on the berry surface had a consistent negative effect on colonization. Therefore, at each phenological stage, significantly fewer segments removed from wet than moist berries were colonized. The detrimental effect of free water was furthermore differentially influenced by host phenology; colonization was inhibited more on immature berries than on mature berries, especially during the first stages (3 to 12 hpi). Surface colonization, on the other hand, remained at a constant high level for the duration of the incubation period on mature berries. Colonization trends displayed by segments removed from berries under the sterile regime (Fig. 6) showed that penetration was not influenced by wetness regime. Berries were highly resistant to penetration by the pathogen when immature and less resistant when mature. Furthermore, surface colonization had no direct effect on penetration. At pea-size stage (Fig. 6A), penetration took place soon after germination, and $6.1 \%$ of the segments removed from berries at 6 hpi already yielded the pathogen. However, the frequency then remained at a constant low level at later sampling periods. Penetration was delayed on berries at bunch closure and first occurred during the 24- to 48-hpi period (Fig. 6B). The proportion of sterile segments yielding the pathogen increased marginally from 1.3 to $2.7 \%$ during this period. Penetration, however, steadily increased with incubation time on mature berries. At véraison (Fig. 6C), 3.1, 6.1, 10.7 , and $16.9 \%$ of the segments removed at $6,12,24$, and $48 \mathrm{hpi}$, respectively, yielded the pathogen. Incubation periods longer than $48 \mathrm{hpi}$, however, did not lead to higher penetration levels under any of the wetness regimes. Penetration on ripe berries (Fig. 6D) followed a trend similar to the trend recorded on berries at véraison.
Colonization trends displayed by frozen berries (Fig. 6E-H) showed that passive and active resistance of grape skins to penetration by the pathogen were differentially affected by grape phenology. Berries at pea-size stage generally yielded the pathogen at relatively high frequencies; the frequency of colonization on berries was significantly higher on berries left unsterile before being frozen than on berries that were sterilized. Wetness regime did not significantly affect the proportion of berries colonized under the sterile regime, but significantly affected sporulation under the unsterile regime. A different trend was displayed by berries at bunch closure. None of the berries sterilized and frozen during the 3- to 12-hpi period yielded the pathogen, whereas only $5.3 \%$ of the berries yielded the pathogen when frozen $24 \mathrm{hpi}$. This trend was displayed by both moist and wet berries. Sporulation was, however, significantly affected by wetness on berries left unsterile. When frozen at $6 \mathrm{hpi}, 2$ and $12 \%$ berries incubated under the moist and wet regime, respectively, were colonized. Frequencies recorded for berries frozen at 12 hpi were 6 and 14\%, respectively. Trends on berries at véraison and the ripe stages showed that both the passive and active defense mechanisms weakened at maturity. Sporulation first occurred on berries at véraison and the ripe stage when they were frozen 6 hpi. Frequencies at this sampling period were equal $(2.5 \%)$ for the different treatments. Thereafter, penetration proceeded at a significantly higher rate on wet than on moist berries. Penetration followed a similar pattern on ripe berries.

Symptom expression. Disease symptoms did not develop during the 14-day period on the berries transferred to dry perspex chambers, irrespective of phenological stage, incubation period, or wetness regime.

\section{DISCUSSION}

Our study on grape berry surfaces gives perspective to the role of mode of infection by $B$. cinerea in disease epiphytotics in the vineyard. Working with conidial clusters of B. cinerea on mature berries, Nair and Allen (43) showed that a 14-h wetness period is needed to give $63 \%$ symptomatic berries at $23^{\circ} \mathrm{C}$. Working with single airborne conidia we found that berries at different phenological stages remained asymptomatic after extended periods ( 3 to $96 \mathrm{~h}$ ) of moist or wet incubation. Although wetness markedly influenced germination, morphogenesis of germ tubes, appressorium formation, and germling viability, infection on wet berries was not favored by an enhanced surface colonization potential $(7,73)$. Other studies (25) with airborne conidia confirmed this trend on table grape cvs. Barlinka and Waltham Cross, and wine grape cvs. Merlot, Chenin Blanc, and Shiraz. This finding suggests that when high humidity $( \pm 93 \% \mathrm{RH})$ prevails in nature, airborne conidia will have an equal potential to infect dry and wet berry surfaces. Furthermore, a wetness period ranging from 3 to 48 hpi will have no effect on the establishment of infection on immature berries, but the frequency will be increased on mature berries. However, according to our findings, these infections per se should not lead to symptom expression at either phenological stages in the vineyard. Thus, this mode of infection should not contribute to a gradual built-up of secondary inoculum, and to $B$. cinerea epiphytotics. This finding can have a major impact on the validation of disease prediction models for grapevine. These models are primarily based on the induction of symptoms by conidia growing in a cluster after inoculation with conidial suspensions on mature berries. Based on these findings, $B$. cinerea bunch rot epidemics on grapes are described as weather driven $(3,67)$, inoculum driven (46), or, depending on climatic conditions, determined by inoculum or weather conditions (44).

No significant differences were found in germination, hyphal growth, and appressorium formation of conidia of $B$. cinerea growing in a cluster on detached immature and mature grapes (23). In the current study, fluorescence microscopy revealed that solitary conidia of $B$. cinerea behave differently than clusters of conidia on grape surfaces. Under the moist regime, growth was invariably restricted irrespective of berry ripeness. Conidia germinated more extensively on wet berries, but germ tube elongation differed at different phenological stages. Fewer germlings formed appressoria on berries at bunch closure than on berries at the other stages. Furthermore, on moist berries, conidia formed one protoappressorium, or in some instances one simple appressorium. On wet berries, a variety of appressoria were formed. On grapes, the primary sites for penetration are considered to be stomata and microfissures in the berry skin $(2,57,66)$. Attempted penetration by solitary conidia was never through stomata or microfissures, but was direct, irrespective of germ tube length, number, or branching. Our histological studies with $B$. cinerea on stone fruit $(20)$ and grapes $(26,27,29)$ revealed that conidia suspended in droplets were inclined to settle in the center of the droplet, which caused an agglomeration of conidia. This action forced conidia to settle around or on stomata and to enter these sites. They germinated and hyphal mats formed on the berry's surface in most droplets. We also noted that microfissures, which acted as avenues for penetration by hyphal mats, developed with time in the cuticle under the droplet. In these studies, synergistic effects of numerous conidia growing in a cluster on a single site on the host surface possibly masked the effects of berry exudates, skin components, and active defense described here. 

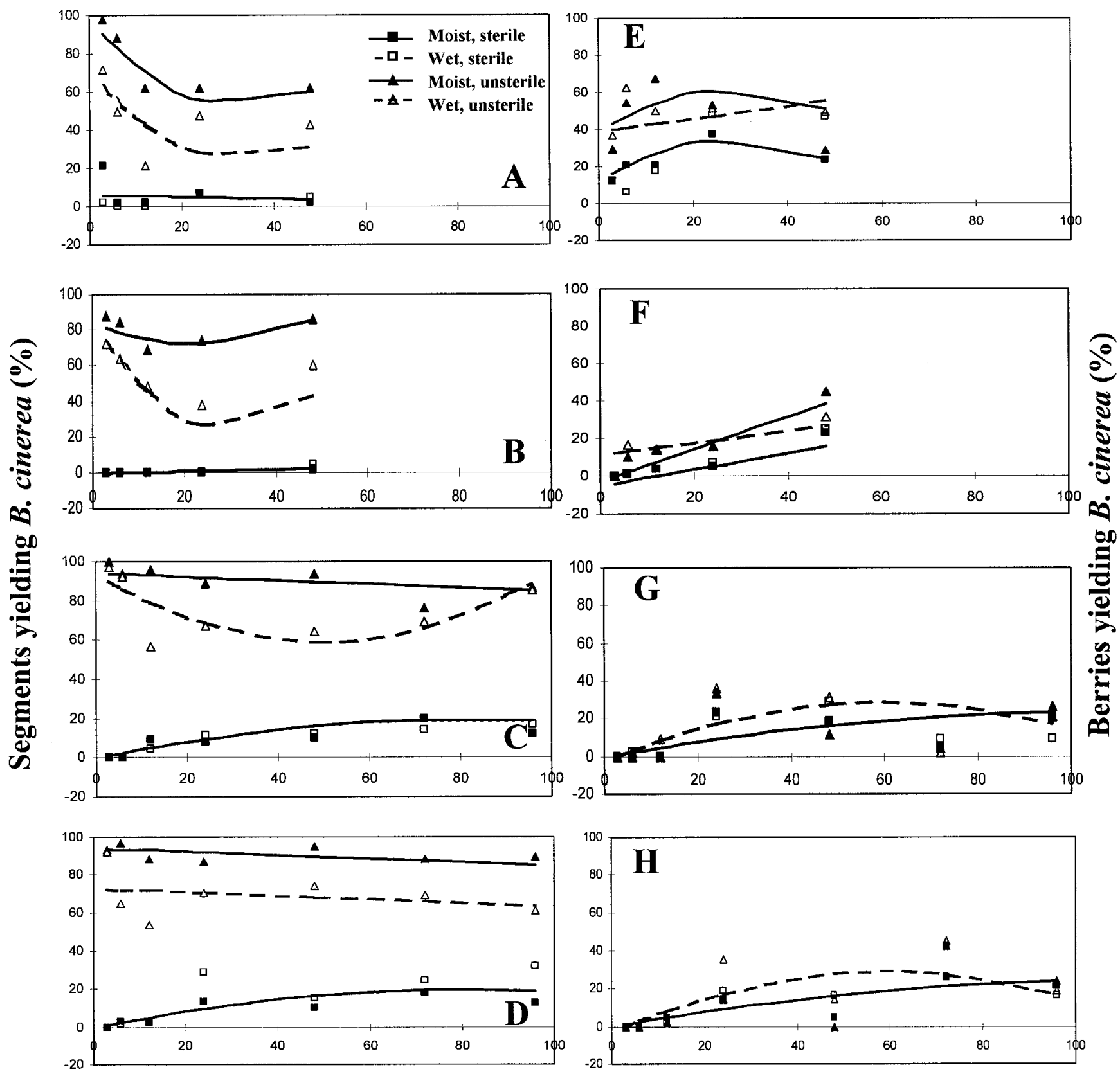

\section{Incubation period (h)}

Fig. 6. Regression models for the effects of wetness regime and incubation period on the surface colonizing ability and infectivity of solitary Botrytis cinerea conidia on cv. Dauphine grapes at different phenological stages. A, Pea-size: sterile segments, moist and wet $\left(Y=5.90-0.049 X, R^{2}=0.85, P=\right.$ $0.7489)$; unsterile segments, moist $\left(Y=98.19-2.72 X+0.04 X^{2}, R^{2}=0.85, P=0.0001\right)$; and unsterile segments, wet $\left(Y=70.57-2.72 X+0.04 X^{2}, R^{2}=\right.$ $0.85, P=0.0001)$. B, Bunch closure: sterile segments, moist and wet $\left(Y=-0.845+0.068 X, R^{2}=0.96, P=0.4771\right)$; unsterile segments, moist $(Y=83.86-$ $\left.1.022 X+0.022 X^{2}, R^{2}=0.96, P=0.0630\right)$; and unsterile segments, wet $\left(Y=83.86-3.914 X+0.064 X^{2}, R^{2}=0.96, P=0.0001\right)$. C, Véraison: sterile segments, moist $\left(Y=-0.447+0.491 X-0.003 X^{2}, R^{2}=0.57, P=0.0001\right)$; sterile segments, wet $\left(Y=0.447+0.491 X-0.003 X^{2}, R^{2}=0.57, P=0.0001\right)$; unsterile segments, moist $\left(Y=93.96-0.089 X, R^{2}=0.97, P=0.0311\right)$; unsterile segments, wet $\left(Y=93.96-1.4 X+0.014 X^{2}, R^{2}=0.97, P=0.0001\right)$. D, Ripe: sterile segments, moist $\left(Y=0.447+0.491 X-0.003 X^{2}, R^{2}=0.57, P=0.0001\right)$; sterile segments, wet $\left(Y=-0.447+0.491 X-0.003 X^{2}, R^{2}=0.57, P=\right.$ $0.0001)$; unsterile segments, moist $\left(Y=72.33-0.089 X, R^{2}=0.97, P=0.0311\right)$; and unsterile segments, wet $\left(Y=93.96-0.089 X+0.014 X^{2}, R^{2}=0.97, P=\right.$ $0.0311)$. E, Pea-size: sterile berries, moist and wet $\left(Y=11.97+1.55 X-0.027 X^{2}, R^{2}=0.78, P=0.0028\right)$; unsterile berries, moist $(Y=38.77+1.55 X-$ $\left.0.027 X^{2}, R^{2}=0.78, P=0.0028\right)$; and unsterile berries, wet $\left(Y=38.77+0.35 X, R^{2}=0.78, P=0.0800\right)$. F, Bunch closure: sterile berries, moist and wet $(Y=$ $\left.-2.971+0.514 X, R^{2}=0.83, P=0.0001\right)$; unsterile berries, moist $\left(Y=-2.971+0.872 X, R^{2}=0.83, P=0.0001\right)$; and unsterile berries, wet $(Y=10.845+$ $\left.0.330 X, R^{2}=0.83, P=0.0001\right)$. G, Véraison: sterile and unsterile berries, moist $\left(Y=-0.30+0.443 X-0.002 X^{2}, R^{2}=0.46, P=0.0055\right)$ and sterile and unsterile berries, wet $\left(Y=-3.33+1.076 X-0.009 X^{2}, R^{2}=0.46, P=0.0001\right)$. H, Ripe: sterile and unsterile berries, moist $\left(Y=-0.30+0.443 X-0.002 X^{2}\right.$, $\left.R^{2}=0.46, P=0.0055\right)$ and sterile and unsterile berries, wet $\left(Y=-3.33+1.076 X-0.009 X^{2}, R^{2}=0.46, P=0.0001\right)$. Surface colonizing ability is the percentage of segments removed at each incubation period from unsterile berries, or the percentage of unsterile frozen berries, that yielded the pathogen after 14 days of incubation. Infectivity is represented by the percentage of infected segments removed from surface-disinfected berries, or the percentage of sterile frozen berries that yielded the pathogen. Data presented are transformed means, whereas lines are predicted values based on regression equations derived from point data. Separate lines indicate significant differences in trends between treatments. 
Infection studies with conidial suspensions of $B$. cinerea on different hosts demonstrated that increasing densities of conidia led to higher infections and lesion formation $(16,63,69,70)$. Little is known about the relation between conidial density, infection, and subsequent $B$. cinerea berry rot on grape. In most studies where grape berries were artificially inoculated, suspensions containing $\geq 10^{4}$ conidia per milliliter were used as a standard procedure to induce symptom expression $(1,3,6,11,39,40,42,45,50,68)$. Warren et al. (72) showed that suspensions containing $\geq 10^{4}$ conidia per milliliter were required on on-vine inflorescences and bunches of the highly susceptible wine grape cv. Chardonnay to induce symptom expression on frozen inflorescences or berries. Hill et al. (23) calculated that, from a total of 3,500 conidia per $15.9-\mathrm{mm}^{2}$ cuticle surface, only 1 to 2 conidia were able to penetrate the isolated cuticle layer. The findings of these workers suggest that disease expression by $B$. cinerea on grapes is not dependent upon inoculum density. The data of Coertze and Holz (8) on the infectivity of single airborne $B$. cinerea conidia, and that symptom expression is not governed by conidium density on berries, substantiate this hypothesis. By using a differential set of segment isolation and freezing techniques on sterile and nonsterile berries at different phenological stages, we proved that infections in grape berry cheeks established by this infection mode were few. These findings suggest that the importance of another primary infection event in the vineyard, namely natural infection by airborne conidia of the other parts of bunches, might have been overlooked. Pezet and Pont (56) showed, in their histological studies of laboratory-inoculated bunches, that $B$. cinerea colonizes the stamens and invades their base situated on the receptacle. From there it spreads to the pedicel and vascular tissue in berries. Other studies $(25,27,28)$ showed that $B$. cinerea infection generally occurs in the other morphological parts of grape bunches, and, therefore, is not exclusive to the grape berry cheek or pistil. These findings imply that incipient infections can cause both mid- or late-season bunch rot following a period of fungal latency in the rachis, laterals, or pedicels, and not in berry cheeks and style ends. Therefore, disease management strategies should concentrate on the prebunch stage, and on effective coverage of the internal bunch parts.

Our finding that grape skins provide an effective barrier to penetration by solitary conidia confirmed the decisive role of wounding in both symptom expression and the epidemiology of $B$. cinerea on grapevine. Wounds are regarded as major entry sites for the pathogen on grapes $(8,15,23,45)$. Grapes can be wounded by insects, frost, hail, windblown sand, sunburn, or the rapid uptake of water leading to splitting $(34,62)$. Trends followed by solitary conidia on the berry surface described here, however, suggest that, in the vineyard, a combination of fresh wounds and new inoculum is needed for successful wound infection. Insects may play a very prominent role in this event. Fermaud and Le Menn (17) showed that larvae of Lobesia botrana carried viable conidia of $B$. cinerea externally or internally. According to Fermaud and Le Menn (18), the introduction of conidia into wounds by $L$. botrana is important in the initiation of rot during the stages before véraison. Insects can be considered main suppliers of conidial clusters for infection and may, therefore, be responsible for disease outbreaks that often occur in vineyards (47).

\section{LITERATURE CITED}

1. Avissar, I., and Pesis, E. 1991. The control of postharvest decay in table grapes using acetaldehyde vapors. Ann. Appl. Biol. 118:229-237.

2. Bessis, R. 1972. Étude de l'évolution des stomates et des tissus péristomatiques du fruit de la vigne. C. R. Acad. Sci. (Paris) 274:21582161.

3. Broome, J. C., English, J. T., Marois, J. J., Latorre, B. A., and Aviles, J. C. 1995. Development of an infection model for Botrytis bunch rot of grapes based on wetness duration and temperature. Phytopathology 85:97-102.

4. Brown, G. E. 1989. Host defenses at the wound site on harvested crops. Phytopathology 79:1381-1384

5. Bulit, J., and Verdu, D. 1973. Annual variations in the aerial sporing of Botrytis cinerea in a vineyard. Proc. Eur. Botrytis Symp. 28 June-1 July, Teresin, Poland.

6. Chardonnet, C., L'Hyvernay, A., and Doneche, B. 1997. Effect of calcium treatment prior to Botrytis cinerea infection on the changes in pectic composition of grape berry. Physiol. Mol. Plant Pathol. 50:213-218.

7. Clark, C. A., and Lorbeer, J. W. 1976. Comparative histopathology of Botrytis squamosa and Botrytis cinerea on onion leaves. Phytopathology 66:1279-1289.

8. Coertze, S., and Holz, G. 1999. Surface colonization, penetration, and lesion formation on grapes inoculated fresh or after cold storage with single airborne conidia of Botrytis cinerea. Plant Dis. 83:917-924.

9. Corbaz, R. 1972. Etudes des spores fongiques captées dans l'air. Phytopathol. Z. 74:318328 .

10. Creasy, L. L., and Coffee, M. 1988. Phytoalexin production potential of grape berries. J. Am. Soc. Hortic. Sci. 113:230-234.

11. De Kock, P. J., and Holz, G. 1991. Colonization of table grapes by Botrytis cinerea in the Western Cape province. Phytophylactica 23:73-80.

12. Doss, R. P., Potter, S. W., Chastagner, G. A., and Christian, J. K. 1993. Adhesion of nongerminated Botrytis cinerea conidia to several substrata. Appl. Environ. Microbiol. 59:1786-1791.

13. Doss, R. P., Potter, S. W., Soeldner, A. H., Christian, J. K., and Fukunaga, L. E. 1995. Adhesion of germlings of Botrytis cinerea. Appl. Environ. Microbiol. 61:260-265.

14. Duncan, R. A., Stapleton, J. J., and Leavitt, G. M. 1995. Population dynamics of epiphytic mycoflora and occurrence of bunch rots of wine grapes as influenced by leaf removal. Plant Pathol. 44:956-965.

15. Du Plessis, S. J. 1937. Botrytis rot of grapes, and its control during 1933-1934. Farming SA 9:395-397, 439-442.
16. Eden, M. A., Hill, R. A., Beresford, R., and Stewart, A. 1996. The influence of inoculum concentration, relative humidity, and temperature on infection of greenhouse tomatoes by Botrytis cinerea. Plant Pathol. 45:798-806.

17. Fermaud, M., and Le Menn, R. 1989. Association of Botrytis cinerea with grape berry moth larvae. Phytopathology 79:651656.

18. Fermaud, M., and Le Menn, R. 1992. Transmission of Botrytis cinerea to grapes by grape berry moth larvae. Phytopathology 82:1393-1398.

19. Fourie, J. F. 1992. Postharvest decay of stone fruit: infection and latency of Botrytis cinerea. Ph.D. (Agric.) diss. University of Stellenbosch, Stellenbosch, South Africa.

20. Fourie, J. F., and Holz, G. 1995. Initial infection processes by Botrytis cinerea on nectarine and plum fruit and the development of decay. Phytopathology 85:82-87.

21. Gessler, A., and Jermini, M. 1985. Role of flower infections of grape by Botrytis cinerea and consequences for the spraying schedule. Quad. Vitic. Enol. Univ. Torino 9:245-250.

22. Hill, G. 1985. Suberisation of cell walls: A Defence reaction of grape stem tissue against invading mycelium of Botrytis cinerea. Quad. Vitic. Enol. Univ. Torino 9:229-230.

23. Hill, G. K., Stellwaag-Kittler, F., Huth, G., and Schlösser, E. 1981. Resistance of grapes in different development stages to Botrytis cinerea. Phytopathol. Z. 102:329-338.

24. Holloway, P. J., and Wattendorf, J. 1987. Cutinized and suberinized cell walls. Pages 1-15 in: Handbook of Plant Cytochemistry. Vol II. Other Cytochemical Staining Procedures. H C. Vaughn, ed. CRC Press, Boca Raton, FL.

25. Holz, G. 1999. Behaviour and infection pathways of diverse fungal pathogens on fruit Page 257 in: Conf. Handb. Bien. Aust. Plant Pathol. Soc. Conf. 12th. Canberra, Australia.

26. Holz, G., and Coertze, S. 1996. Growth of separate, individual conidia of Botrytis cinerea on fruit surfaces. Page 47 in: Scientific Programme and Abstracts. XIth Int. Botrytis Symp. Wageningen, the Netherlands.

27. Holz, G., Coertze, S., and Basson, E. J. 1997. Latent infection of Botrytis cinerea in grape pedicels leads to postharvest decay. (Abstr.) Phytopathology 87:S43.

28. Holz, G., Coertze, S., and Basson, E. J. 1998 Infection pathways and latency of Botrytis cinerea in grape bunches. (Abstr.) 7th Int. Congr. Plant Pathol. Edinburgh, Scotland, Vol. 3:6-22.

29. Holz, G., Körte, V., and Coertze, S. 1995. Behavior of Botrytis cinerea on grape, nectarine and plum fruit surfaces under different wetness regimes. Page 56 in: Scientific Programme and Abstracts. Bien. Aust. Plant Pathol. Soc. Conf. 10th. Lincoln University, New Zealand.

30. Hoos, G., and Blaich, R. 1988. Metabolism of stilbene phytoalexins in grapevines: Oxidation of resveratrol in single-cell cultures. Vitis 27:1-12.

31. Ippolito, A., Nigro, F., Lima, G., Castellano, M., Salerno, M., Di Venere, D., Linsalata, V. and Lattanzio, V. 1997. Mechanisms of resistance to Botrytis cinerea in wounds of cured kiwifruit. Acta Hortic. 444:719-724.

32. Jarvis, W. R. 1962. The dispersal of spores of Botrytis cinerea Fr. in a raspberry plantation. Trans. Br. Mycol. Soc. 45:549-559.

33. Jarvis, W. R. 1962. Splash dispersal of spores of Botrytis cinerea Pers. Nature (London) 193:599.

34. Jarvis, W. R. 1980. Epidemiology. Pages 219250 in: The Biology of Botrytis. J. R. ColeySmith, K. Verhoeff, and W. R. Jarvis, eds. Academic Press, New York.

35. Kerssies, A. 1990. A selective medium for 
Botrytis cinerea to be used in a spore-trap. Neth. J. Plant Pathol. 96:247-250.

36. Kosuge, T., and Hewitt, W. B. 1964. Exudates of grape berries and their effect on germination of conidia of Botrytis cinerea. Phytopathology 54:167-172.

37. Langcake, P. 1981. Disease resistance of Vitis spp. and the production of the stress metabolites resveratrol, $\varepsilon$-viniferin, $\alpha$-viniferin and pterostilbene. Physiol. Plant Pathol. 18:213226.

38. Louis, C., Girard, M., Kuhl, G., and LopezFerber, M. 1996. Persistence of Botrytis cinerea in its vector Drosophila melanogaster. Phytopathology 86:934-939.

39. Marois, J. J., Bledsoe, A. M., Bostock, R. M., and Gubler, W. D. 1987. Effects of spray adjuvants on development of Botrytis cinerea on Vitis vinifera berries. Phytopathology 77:1148-1152.

40. Marois, J. J., Bledsoe, A. M., Gubler, W. D., and Luvisi, D. A. 1986. Control of Botrytis cinerea on grape berries during postharvest storage with reduced levels of sulfur dioxide. Plant Dis. 70:1050-1052.

41. McClellan, W. D., and Hewitt, B. 1973. Early Botrytis rot of grapes: Time of infection and latency of Botrytis cinerea Pers. in Vitis vinifera L. Phytopathology 63:1151-1157.

42. Nair, N. G. 1985. Fungi associated with bunch rot of grapes in the Hunter Valley. Aust. J. Agric. Res. 36:435-442.

43. Nair, N. G., and Allen, R. N. 1993. Infection of grape flowers and berries by Botrytis cinerea as a function of time and temperature. Mycol. Res. 97:1012-1014.

44. Nair, N. G., and Balasubramaniam, R. 1995. Operational research on Botrytis bunch rot disease management in Australian and New Zealand viticulture. Aust. N. Z. Wine Ind. J. 10:237-240.

45. Nair, N. G., Emmett, R. W., and Parker, F. E. 1988. Some factors predisposing grape berries to infection by Botrytis cinerea. N. Z. J Exp. Agric. 16:257-263.

46. Nair, N. G., Guilbaud-Oulton, S., Barchia, I., and Emmett, R. 1995. Significance of carry over inoculum, flower infection and latency on the incidence of Botrytis cinerea in berries of grapevines at harvest in New South Wales. Aust. J. Exp. Agric. 35:1177-1180.

47. Nair, N. G., and Hill, G. K. 1992. Bunch rot of grapes caused by Botrytis cinerea. Pages 147-169 in: Plant Diseases of International Importance. Vol III: Diseases of Fruit Crops. J. Kumar, H. S. Chaube, U. S. Singh and A. N. Mukhopadhyoy, eds. Prentice-Hall, New Jersey.

48. Nair, N. G., and Nadtotchei, A. 1987. Sclero- tia of Botrytis as a source of primary inoculum for bunch rot of grapes in New South Wales, Australia. J. Phytopathol. 119:42-51.

49. Nair, N. G., and Parker, F. E. 1985. Midseason bunch rot of grapes: an unusual disease phenomenon in the Hunter Valley, Australia. Plant Pathol. 34:302-305.

50. Nelson, K. E. 1951. Effect of humidity on infection of table grapes by Botrytis cinerea. Phytopathology 41:859-864.

51. Nelson, K. E. 1956. The effect of Botrytis infection on the tissue of Tokay grapes. Phytopathology 46:223-229.

52. Northover, J. 1987. Infection sites and fungicidal prevention of Botrytis cinerea bunch rot of grapes in Ontario. Can. J. Plant Pathol. 9:129-136.

53. O'Brien, T. P., and McCully, M. E. 1981. The study of Plant Structure Principles and Selected Methods. Termarcarphi Pty. Ltd. Melbourne, Australia.

54. Padgett, M., and Morrison, J. C. 1990. Changes in the grape berry exudates during fruit development and their effect on the mycelial growth of Botrytis cinerea. J. Am. Soc. Hortic. Sci. 115:269-273.

55. Pezet, R., and Pont, V. 1984. Botrytis cinerea: Activité antifongique dans les jeunes grappes de Vitis vinifera, Varieté Gamay. Phytopathol. Z. 111:73-81.

56. Pezet, R., and Pont, V. 1986. Infection florale et latence de Botrytis cinerea dans les grappes de Vitis vinifera (var. Gamay). Rev. Suisse Vitic. Arboric. Hortic. 18:317-322.

57. Pucheu-Planté, B., and Mercier, M. 1983. Étude ultrastructurale de l'interrelation hôteparasite entre le raisin et le champignon Botrytis cinerea: exemple de la pourriture noble en Sauternais. Can. J. Bot. 61:17851797.

58. Reifschneider, F. J. B., and Boiteux, L. S. 1988. A vacuum-operated settling tower for inoculation of powdery mildew fungi. Phytopathology 78:1463-1465.

59. Salinas, J., Glandorf, D. C. M., Picavet, F. D., and Verhoeff, K. 1989. Effects of temperature, relative humidity and age of conidia in the incidence of spotting on gerbera flowers caused by Botrytis cinerea. Neth. J. Plant Pathol. 95:51-64.

60. Sarig, P., Zahavi, T., Zutkhi, Y., Yannai, S., Lisker, N., and Ben-Arie, R. 1996. Ozone for control of post-harvest decay of table grapes caused by Rhizopus stolonifer. Physiol. Mol. Plant Pathol. 48:403-415.

61. Sarig, P., Zutkhi, Y., Monjauze, A., Lisker, N., and Ben-Arie, R. 1997. Phytoalexin elicitation in grape berries and their susceptibility to Rhizopus stolonifer. Physiol. Mol.
Plant Pathol. 50:337-347.

62. Savage, S. D., and Sall, M. A. 1983. Botrytis bunch rot of grapes: the influence of selected cultural practices on infection under California conditions. Plant Dis. 67:771-774.

63. Sirjusingh, C., Sutton, J. C., and Tsujita, M. J. 1996. Effects of inoculum concentration and host age on infection of geranium by Botrytis cinerea. Plant Dis. 80:154-159.

64. Snedecor, G. W., and Cochran, W. G. 1980. Statistical Methods. 7th Ed. Iowa State University Press, Ames.

65. Spotts, R. A., and Holz, G. 1996. Adhesion and removal of conidia of Botrytis cinerea and Penicillium expansum from grape and plum fruit surfaces. Plant Dis. 80:688-691.

66. Stalder, I. 1953. Undersuchungen über die Graufäule. Phytopathol. Z. 22:315-344, 345380.

67. Strizyk, S. 1983. Modele d'etat potentiel d'infection application au Botrytis cinerea. Version 1983. Association de coordination technique agricole. France.

68. Thomas, C. S., Marois, J. J., and English, J. T. 1988. The effects of wind speed, temperature and relative humidity on development of aerial mycelium and conidia of Botrytis cinerea on grape. Phytopathology 78:260265.

69. Van den Heuvel, J. 1981. Effect of inoculum composition on infection of French bean leaves by conidia of Botrytis cinerea. Neth. J. Plant Pathol. 87:55-64.

70. Van den Heuvel, J., and Waterreus, L. P. 1983. Conidial concentration as an important factor determining the type of prepenetration structures formed by Botrytis cinerea on leaves of French bean (Phaseolus vulgaris). Plant Pathol. 32:263-272.

71. Vercesi, A., Locci, R., and Prosser, J. I. 1997. Growth kinetics of Botrytis cinerea on organic acids and sugars in relation to colonization of grape berries. Mycol. Res. 101:139-142.

72. Warren, M. A., Becker, N., Mebalds, M., and Glenn, D. C. 1999. The link between spore concentration, flower infection and subsequent bunch rot caused by Botrytis cinerea in winegrapes. Page 293 in: Conf. Handb. Bien. Aust. Plant Pathol. Soc. Conf. 12th. Canberra, Australia.

73. Wildman, H. G., and Parkinson, D. 1981 Comparison of germination of Cladosporium herbarum and Botrytis cinerea conidia in vitro in relation to nutrient conditions on leaf surfaces. Can. J. Bot. 59:854-861.

74. Zar, J. H. 1984. Biostatistical Analysis. 2nd ed. Prentice-Hall, Inc., Englewood Cliffs, $\mathrm{NJ}$ 